\title{
Study on the Influence of Success in Winning the 7th Military World Games on Wuhan Sports Industry Development
}

\author{
Yingyue HU, Huan XU \\ The School of Physical Education, Wuhan Business University \\ Wuhan, China \\ 337584093@qq.com \\ musicxuhuan@vip.qq.com
}

\begin{abstract}
In recent years, sports industry has already become an emerging industry in the development of Wuhan city. Its basic structure has been formed, which shows an immeasurable development prospect. Wuhan has successfully won the right to host the 7th Military Games in 2019, which will bring significant effects to the development of Wuhan in various aspects, including culture, politics and economy. The biggest winner will be the sports industry. Beginning with the Military World Games and Wuhan sports industry, this thesis studies from multiple perspectives including economy, culture and construction, and predicts and speculates its negative influences, while affirming its positive influences. Besides, the author proposes solutions in time to help Wuhan sports industry achieve development goals of modernization, internationalization and ecologicalization.
\end{abstract}

Keywords—Military World Games; Sports Industry; Wuhan

\section{INTRODUCTION}

The Military World Games will be one of the biggest international events held in China after the Beijing Olympic Games and also the international grand meeting undertaken by Wuhan with the highest level, the widest range and the most extensive influences. It not only symbolizes the great stage of sports, but also can accelerate urban construction in a short time, improve the cultural level, improve employment of populations and enhance urban popularity, so that economy of Wuhan or even entire sports industry will gain the greater benefits and development prospect. The Military World Games in Wuhan is a challenge and also an opportunity. However, there are few studies on the topic with the great significance for Wuhan sports industry, thus the author in this thesis will elaborate possible influences of Military World games from economic and cultural aspects by combining with development status of Wuhan sports industry from the perspective of the Military World Games and also will come up with suggestion on using large-scale sports events to make sports industry survive and develop.

\section{A. Overview of the Military World Games 2019}

The Military World Games is a military contest founded in 1995 once every four years. Organized by the International Military Sports Council, it is called as "the Military Olympic Games". The stadiums in 2019 will be distributed in each urban area of Wuhan. In addition to the conventional contest, it will set up parachuting, military shooting, military pentathlon, air force pentathlon and navy pentathlon. This Military World Games will depend on surrounding garrison camp and military school stadiums. It is reported that the event will create the history of first time for twice: to focus on newly establishing the athletes' village for the first time and to hold all contests in a city for the first time [1]. Wuhan arranges 35 stadium facilities including 10 newly established facilities and 19 facilities of maintenance and reconstruction in Guanggu, Huangjia Lake, Zhuankou and Houhu in this Military World Games. Among which, it gets involved in a newly established army and four armies of maintenance and reconstruction. Meanwhile, multiple stadiums are used for undertaking the opening and closing ceremony, athletes' accommodations, news propaganda and radio news.

\section{STATUS ANALYSIS OF WUHAN SPORTS INDUSTRY}

\section{A. The General Level Status Analysis of Wuhan Sports Industry}

According to joint data latest issued by Wuhan Statistical Bureau and Sports Bureau, total scale of Wuhan sports industry is 20.9 billion RMB and added value is 10.33 billion RMB, occupying $0.95 \%$ of Wuhan Gross Domestic Product(GDP). Based on the overseas mature sports market, the total value of the sports industry in the future is expected to reach $10 \%$ of GDP [2]. Nowadays, Wuhan sports industry is relatively small, but sports industry undoubtedly will become the wide development space with the continuous economic development of Wuhan. 


\section{B. Structural Analysis of Wuhan Sports Industry}

The complete sports industry structure can improve the overall efficiency of sports industry [3]. In recent years, the scale of Wuhan sports industry is constantly expanding. Even if Wuhan sports industry structure is slightly superior to the national average level of sports industry, the internal industry structure still has lots of problems with the constant expansion of economic aggregate. The long-term accumulated structural contradictions are relatively prominent. Moreover, it is kept in the state of polarization. It is said Wuhan sports industry structure has been kept in two contradictions up to now: one is the contradiction between supply and demand of sports products; the other one is the contradiction of sports industry development and can't meet the public demands, thus it is urgent to adjust and optimize the structure [4].

Athletic performance structure: At present, permanent resident populations of Wuhan are 8.5 million. There are 17 performance places and 8 singing halls with more than 800 seats. There are over 400 entertainers registered in the city. Various entertainers in each entertainment venue exceed one thousand people, but people who engage in sports entertainment performance industry are relatively insufficient, accounting for $35.7 \%$ of all entertainers. The overall level of entertainment industry is poor. At present, Wuhan has held lots of sports events, such as Wuhan Marathon, Wuhan Tennis and Badminton Asian Championship, etc. These events have a small scale and don't have a strong international connection. Actually, Wuhan is still short of large-scale events.

Facility structure: infrastructure construction of sports not only can promote the development of regional sports industry, but also is the important measurement standard for development status of regional sports industry. According to the distribution diagram of Wuhan stadiums, there are about 3000 representative stadiums in Wuhan, but the field distribution is seriously unbalanced. About $68 \%$ of stadiums are distributed in schools, while $20 \%$ of stadiums are located in each enterprise and military base. Communities or other places have few facilities. In addition, from the perspective of regional distribution, Wuchang District, Xinzhou District and Caidian have more stadiums, while Jiangxia District has a scanty few facilities. Meanwhile, utilization of public stadiums is less comprehensive. Even if majorities of stadiums are distributed in each school and belong to the public welfare places, most of schools just regard stadiums as a place for teaching and professional training and don't open it for utilization. By taking the swimming pools as examples, swimming pools can be seen everywhere. However, due to expensive price and limitation of personnel utilization, many residents can't afford and use it. In summer, residents swim in rivers. This not only causes inconvenience for traffic, but also shows safety loopholes.

Sports product structure: sports product is mainly divided into physical products and service products. By sorting out and analyzing Wuhan data in 2015, it could be observed that gross output and growth value of Wuhan sports service industry in 2015 were about 5.24 billion RMB and 2.21 billion RMB, respectively, accounting for $25 \%$ and $21.4 \%$ of gross output and added value in Wuhan sports industry. Gross output and added value of sports articles and relevant product manufacturing industry reached 13.03 billion RMB and 8.11 billion RMB, respectively, accounting for $62.4 \%$ and $78.6 \%$, showing that sales industry growth of sports products in Wuhan is fast. The entire growth of sports service industry is rapid and sales status of physical incomes is relatively good. The service industry is greatly increased, but the situation is not objective relative to the sales industry. Particularly, the market performance industry is waiting for development. Wuhan has the ability to hold the large-scale events, thus to grasp largescale events is an important approach to develop Wuhan sports industry structure.

\section{INFLUENCES OF THE MILITARY WORLD GAMES ON WUHAN SPORTS INDUSTRY}

\section{A. Influences of the Military World Games on Wuhan Urban Construction}

Improve ecological environment and accelerate Wuhan infrastructure construction: Wuhan is accelerating construction of infrastructure projects in 44 cities. Audited by the Executive Committee of Wuhan Military World Games, 27 contest events of the Military World games are arranged in 35 stadiums. There are 10 newly established projects, 19 projects in maintenance and reconstruction, as well as an athletes' village and a media center. It is predicted that the investment will reach more than 10 billion RMB. In the environment construction, 217 roads for more than 800 kilometers conduct the comprehensive beautification, afforestation and quantification from the ground, façade to air. Moreover, the city focuses on rectifying the express way of the Yangtze-Han River and the Huangjia Lake Avenue. It is predicted that the total assets will reach more than 140 billion RMB. Based on it, the application for the Military World Games will promote the improvement of Wuhan and surrounding ecological environment, while enhancing Wuhan infrastructure development.

Realize standardization for Wuhan sports industry structure and improve technological level: sports industry structure optimization is a dynamic process. The sports industry structure optimization is the precondition to realize coordinative development for sports industry. Since the reform and opening-up, Wuhan sports industry structure has been small to large and single to concrete, showing constant perfection. Relative to 10 years ago, the current structure has been greatly changed. The basic structural system has been formed. Unfortunately, Wuhan sports industry development doesn't have a relatively obvious development prospect. The government often neglects the sports industry development and doesn't give a convincing scheme system for management and operation of Wuhan sports industry. The rationality and senior level of sports industry is poor. Also, economic mechanism is insufficiently complete, so that the sports market still has lots of loopholes. Service industry has the low proportion. Internal structure development is slow. Also, it should be further improved and enhanced. The Military World games makes the government has to comprehensively rectify Wuhan industrial structure and management system. In order to hold the Military World Games successfully and maximize development earnings, it is necessary to perfect, modify and formulate the 
better sports system and relevant laws and regulations, integrate market institutions, and take some measures to the monopolistic market.

\section{B. Influences of the Military World Games on Wuhan Sports Economy}

Drive the investment in stadiums and relevant facilities and realize commercial value: Nowadays, sports events become an important chance for commercial development and operation. The events are really combined with commerce. In the late November 2017, the Committee of the Military World Games gave a collection scheme for sponsors and recruited partners, sponsors, exclusive suppliers and suppliers. The product categories sponsored are extensively extensive, distributed in each industry, such as bank, insurance, beer or even network equipment, etc. Moreover, it promises to refer to 2008 Beijing Olympic Games and combine with features of Wuhan Military World Games to customize multiple types of earnings for sponsors, thus enterprises can receive the greater development through the platform of the Military World Games and get a win-win result. It is reported that sponsors are allowed to use the name of Military World Games in line with the enterprise development. Meanwhile, exclusive right of products or services and preferential right of advertising equipment in the public places are provided. Also, sponsors are allowed to sell their products in major places of the Military World Games. In terms of enterprises, this undoubtedly provides an excellent channel for enterprises to promote and sell enterprise products or services, thus it inevitably will attract the attention of media and industry. The investment in real estate, construction, technical communication and environment protection will be dramatically increased. Until now, Darley reaches the cooperative consensus with Wuhan Business School in stadium design and construction of Equestrian Contest in the Military World Sports 2019 from the perspective of talent cultivation, horse import and management and provides multi-aspect sponsorship. Meantime, China Construction Bank (CCB) and Industrial and Commercial Bank of China (ICBC) are also intended to provide financial and bank services for the Wuhan Military World Games. The listed company Career International also has signed an agreement with the Military World games to be the official chief strategic partner of human resources in Wuhan Military World Games 2019, providing a series of professional services for the Wuhan Military World Games in human resources. Besides, selling of media broadcasting rights, collection of tickets, and development sales of derivatives will bring some economic earnings to the Military World Games.

Attract visitors to visit Wuhan and drive the tourism industry development: During the Military World Games, Wuhan tourism industry depends on the abundant tourism resources of Wuhan, showing the important significance on driving Wuhan national economic development. Ten thousands of officials and athletes will come to Wuhan, creating the most of domestic and overseas audiences who watch games. Also, it attracts officials, participators and audiences to visit Wuhan by virtue of this chance and become the potential subjects of Wuhan tourism. By inquiring people who go to Wuhan to watch the Military World Games, they consistently show that they will have a chance to know about Wuhan, visit landscapes, scenic spots and historical sites in Wuhan, while watching games. And this trip will be worthwhile. In addition, consumption of international visitors in transportation, communication, shopping and accommodation will far surpass ordinary times. It is predicted that the tourism industry at least will increase 2 billion RMB of incomes. This undoubtedly will promote Wuhan tourism industry development and drive the development and utilization of Wuhan tourism industry. Rationality utilization of this chance will dramatically increase economy of tourism industry and gain good harvest in capital and propaganda.

Drive the sports consumption consciousness of citizens and promote Wuhan sports consumption: according to City Bar of China, Weibo comments and questionnaire result analysis, the Military World Games is concerned by all people around the world. What's more, many Wuhan people think that this contest will surpass the World Cup and Olympic Games. There is no doubt that it will bring billions of economic earnings to Wuhan tourism industry, food industry and service industry, thus the Military World Games absolutely will make people know well with Wuhan, understand sports industry, and develop sports industry. During the period of Military World Games, people around the world watch games in Wuhan and attempt to develop Wuhan surrounding tourism industry and service industry. This will expand the sports consumption to a large extent and drive economic turnover of Wuhan.

Develop the surrounding industry and improve employment of citizens: In order to greatly hold the Military World Games, Wuhan is trying to construct infrastructures and transform the environment. Each area in Wuhan is transforming the road and constructing the metro. The regional construction undoubtedly creates the greater industrial prospect to the architectural industry and design industry. At the same time, with the population increase during the period of Military World Games, gyms, clubs and surrounding industry, tourism industry and service industry will be greatly developed. Talent recruitment will provide more employment choices for Wuhan to some extent.

\section{CONCLUSIONS}

There is a law in the development of the national cities. Generally speaking, it is driven by international events [5]. The Military World Games lays a foundation on Wuhan, while bringing the short-term earnings to Wuhan, so as to rationally use events, positively retain economic earnings of events, realize comprehensive development of each aspect and develop the tourism industry and service industry, thus sports industry can drive the sustainable development of by-product industry, while positively developing. This can create the long-term economic earnings to Wuhan and finally form a relatively perfect capital chain, thus capital is cycled, creating more benefits to the future industry development of Wuhan. 


\section{REFERENCES}

[1] Yu Guowei, Three "First Ones" by the Wuhan Military World Games[N], Yangtze River Daily, 2017-11-25(003).

[2] Huang Shuiping, the Study on Wuhan Citizens' Sports Consumption Status[D], Wuhan Physical Culture Institute, 2017.

[3] Tan Hong and Zhou Min, Chinese Sports Industry Development Status and Tendency Study[J], Journal of Guangzhou Sports University, 2017, 37(05): 28-32.

[4] Wu Feng, the Enlightenment of Overseas Sports Industry Development Experience onChina[M], Ma'anshan Teacher's School, 2017.

[5] Cui Peng, Wang Ying and Ma Zhijun, Influences of Sports Events on the Host City Development[J], Contemporary Sports Technology, 2016, 6(28): $141+143$. 